\title{
3D Morphometric Analysis of Human Vertebrae C3-T3 Using CT Images Reconstruction
}

\author{
Ee Chon Teo ${ }^{1 *}$, Timothy Holsgrove ${ }^{2}$ and Stepanka Haiblikova ${ }^{3}$ \\ ${ }^{1}$ School of Mechanical and Aerospace Engineering, Nanyang Technological University, Singapore \\ ${ }^{2}$ Department of Engineering, University of Exeter, UK \\ ${ }^{3}$ Biomechanics and Medical Instruments, Czech Technical University in Prague, Czech Republic
}

*Corresponding author: Ee Chon Teo, School of Mechanical and Aerospace Engineering, Singapore, Tel: +65 67905529; E-mail: mecteo@ntu.edu.sg Rec Date: Sep 26, 2017; Acc Date: Oct 10, 2017; Pub Date: Oct 15, 2017

Copyright: (C) 2017 Teo EC, et al. This is an open-access article distributed under the terms of the Creative Commons Attribution License, which permits unrestricted use, distribution, and reproduction in any medium, provided the original author and source are credited.

\begin{abstract}
Vertebral morphometry is important for spinal analysis, diseases diagnosis and improved implant designs. New technologies available allow us to develop a simple and efficient process of obtaining accurate data of threedimensional (3D) vertebral geometry to create a wide and comprehensive database of vertebral dimension for further research.

The primary aim of this study is to introduce a simple and precise technique of vertebral dimension measurement. The technique involves the segmentation of CT scans of a Caucasian male cadaver's head and torso specimen to reconstruct 3D images of C1-T3 using 3D imaging processing software (ScanIP Academic, Synopsys Inc.), and 3D modelling software (ANSYS SpaceClaim). A systematic way of defining specific Cartesian coordinate system is done on all reconstructed vertebrae' images and various standard vertebral parameters are determined accordingly. Finally, the data is compared against previous study to verify the reliability of this method.

The results showed similar trend of vertebral parameters dimensions at vertebral level, except that the dimensions obtained from reconstructed model of CT scans are significantly greater than Asian specimen. The technique applied in this study in the measurement of vertebral parameters is reliable and preferred to other earlier previous methods. The greater dimensions obtained from the specimen can be explained by different specimen ethnic origin, as the vertebral parameters of Caucasian population were reported to be larger than Asian population. To support this latter hypothesis and to create more statistically accurate data, further study on more specimens should be carried out.
\end{abstract}

Keywords: CT images; Anatomy; Caucasian; Cervical spine; Thoracic spine; Vertebral measurement

\begin{abstract}
Abbreviations
EPAS: Superior End-Plate Area; $\mathrm{EPA}_{\mathrm{I}}$ : Inferior End-Plate Area; $\mathrm{EPW}_{\mathrm{S}}$ : Superior End-Plate Width; EPW : Inferior End-Plate Width; $\mathrm{EPD}_{\mathrm{S}}$ : Superior End-Plate Depth; EPD $\mathrm{I}$ : Inferior End-Plate Depth; SCD: Spinal Canal Depth; SCW: Spinal Canal Width; $\mathrm{PDH}_{\mathrm{L}}$ : Left Pedicle Height; PDW $_{\mathrm{L}}$ : Left Pedicle Width; TPW: Transverse Process Width; $\mathrm{VBH}_{\mathrm{A}}$ : Anterior Vertebral Body Height; $\mathrm{VBH}_{\mathrm{P}}$ : Posterior Vertebral Body Height; SPL: Spinous Process Length; C1-7 Cervical Vertebrae; T1-T3: Thoracic Vertebrae
\end{abstract}

\section{Introduction}

Although there are many studies conducted to create the comprehensive and accurate database of spinal anatomic parameters, the data are still incomplete. There is a lack of some specific vertebral parameters and the variety of study population is limited. However, there are specific vertebral dimensions, such as the pedicle, which precision is essential for the design and development of spinal implants and instrumentation, and the exact dimensions of the vertebral body and spinal canal are important for the diagnosis and treatment of spinal cord diseases.
In previous studies, three techniques of vertebral dimension measurement have been reported [1-7]. Firstly, the direct anatomical measurement on cadaveric vertebrae either by using linear caliper or more precisely with the aid of three-dimensional digitiser. These measurements have certain drawbacks, such as poor availability of fresh frozen human cadaver specimen, and dried bone geometrical properties are reported to differ from those in vivo [8,9]. Furthermore, certain parameters are measured on the particular anatomical plane, as the desired part of vertebra is neither accessible with caliper nor digitiser. Secondly, to avoid the need of cadavers and precise in vivo measurements, the plain X-rays radiographs are used for direct measurement [1,2,10-13]. However, on plain radiograph, the magnification factor causes inaccuracy as it is roughly estimated [9]. Thirdly, with the introduction of CT scan provided images with better resolution, many researchers started using CT scans for direct $2 \mathrm{D}$ measurement of vertebrae [1,2,13-16]. Drawbacks of this 2D measurement is the limited number of anatomical planes as well as dimension distortion.

In conclusion, all these methods of vertebral morphometry measurement present certain limitations. Thus, with the advent of powerful and high-resolution MRI and CT images and imaging processing software tools, there is an interest in the use of these images to obtain reliable data for treatment and surgical management of spinal diseases. Accordingly, for accurate and reliable vertebral measurement, 
many researchers extracted complete 3D shape of vertebrae obtained from 3D segmentation of either in vivo or cadavers CT or MRI images. In this study, a 3D shape of each vertebra obtained from 3D segmentation of CT images of a cadaveric specimen and its display views in imaging and modelling processing software, have been presented as a new method for accurate measurement of vertebral parameters.

\section{Materials and Methods}

As the purpose of the study is not to create a large database on vertebral parameters at this stage, only CT scan images of head and torso of a cadaveric specimen were used. By performing segmentation of these images in a 3D imaging processing software, and post processing these images in 3D modelling software, a coordinate system was defined for vertebral dimensions measurement. These parameters dimensions are compared against previous results to verify the reliability of the method adopted.

A Caucasian cadaveric male specimen (age 71 years, height 177.8 $\mathrm{cm}$, weight $110 \mathrm{~kg}$ ) with no evidence of spinal disease, although the patient suffered from cardiac disease and underwent angioplasty, was used in the current study. The CT images of head and torso specimen were obtained using CT Scanner [Siemens Somatom Definition Flash] with $0.6 \mathrm{~mm}$ slice thickness and $512 \times 512$ matrix.

From these CT images, segmentation was performed using 3D imaging processing software (ScanIP Academic, Synopsys Inc.) to reconstruct $3 \mathrm{D}$ models of the vertebrae individually. For this reconstruction, masks of each vertebra were created by painting the bone region of each slice. The stacked 3D model was then smoothened with recursive Gaussian filter with sigma 0.5 in all axes. Finally, the model was imported as STL files into ANSYS SpaceClaim software where the measurement of vertebral parameters was performed.

Prior to the measurement, the orientation and position of the Cartesian XYZ-coordinate system on the vertebral model was defined based on the method used by Tan et al. [7] Panjabi et al. [3] and Zindrick et al. [13]. They defined the origin of the coordinate system at the centroid of the superior end-plate (EPs) with Z-axis normal to the reference XY-plane defined based on the posterior wall of the vertebral body.

Accordingly, to set the origin and orientation of the Cartesian XYZcoordinate system on the reconstructed 3D model of the vertebra, firstly, with the aid of ANSYS SpaceClaim software, the plane of EPs was created by random selection of three points that were far apart on the superior EPs. Then, the superior EPs was outlined according to the vertebral 3D model projection into the EPs plane to create the EPs area (Figure 1).

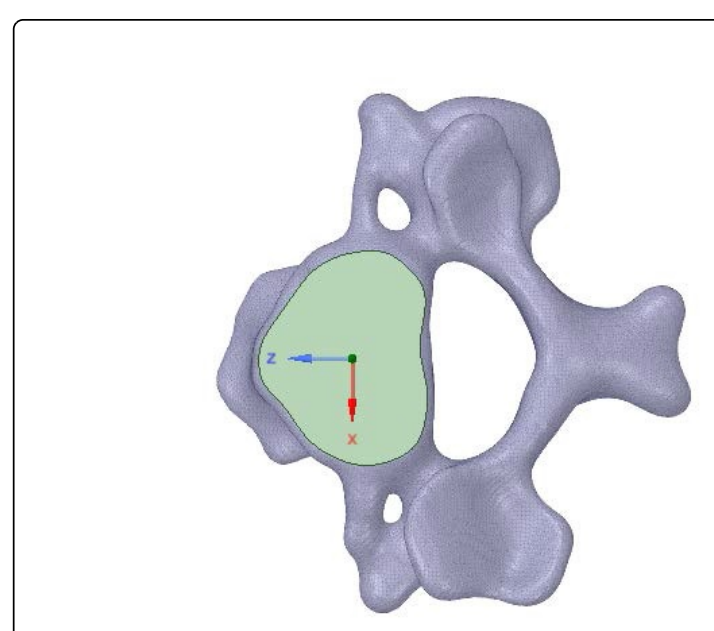

Figure 1: Creation of the superior end-plate area.

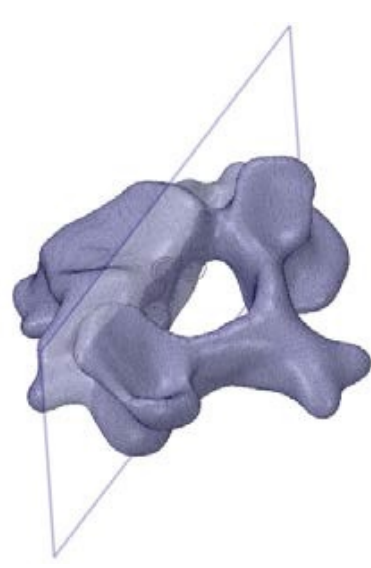

Figure 2: Creation of the reference plane by selection of three points of the posterior vertebral body wall.

A volume of $1 \mathrm{~mm}$ thickness of the EPs area was created and its centroid was computed and determined. Secondly, three points on the posterior wall of vertebral body were selected to create the reference XY-plane (Figure 2).

Subsequently, the final XYZ-coordinate system was orientated with reference to this XY-plane and its origin moved to the centroid of the surface of the EPs.

Based on the defined XYZ-coordinate system, quantitative 3D anatomical parameters, as described in Table 1, were measured on each vertebra $\mathrm{C} 3-\mathrm{T} 3$.

\begin{tabular}{|l|l|l|}
\hline TPW & Transverse process width & $\begin{array}{l}\text { Measured from the posterior view parallel to the frontal plane; horizontal connection of the most } \\
\text { distant points of transverse process. }\end{array}$ \\
\hline SPL & Spinous process length & $\begin{array}{l}\text { Measured from the lateral view as the distance between the coordinate system origin and the } \\
\text { most distant point of the spinous process in the horizontal direction }\end{array}$ \\
\hline EPW & End plate width & $\begin{array}{l}\text { Measured from the posterior view parallel to the frontal plane; due to the complicated shape of } \\
\text { vertebral body, the superior and inferior EPW measured differently; EPWs measured as a }\end{array}$ \\
\hline
\end{tabular}


Citation: $\quad$ Teo EC, Holsgrove T, Haiblikova S (2017) 3D Morphometric Analysis of Human Vertebrae C3-T3 Using CT Images Reconstruction. J

\begin{tabular}{|c|c|c|}
\hline & & $\begin{array}{l}\text { horizontal distance between the tip points of superior end-plate, the EPWi measured as the } \\
\text { horizontal distance between two most distant points of the inferior end-plate. }\end{array}$ \\
\hline EPD & End plate depth & $\begin{array}{l}\text { Measured from the lateral view; the depth established as the horizontal distance between the two } \\
\text { most distal points of either superior or inferior end-plate; to determine EPDs, the plane needed to } \\
\text { be moved in } x \text { direction so as the side part of the vertebra did not block the view. }\end{array}$ \\
\hline EPA & End plate area & $\begin{array}{l}\text { Determined by the process described previously in the orientation of the vertebra section; } \\
\text { measured on the plane parallel to the end-plate surface. }\end{array}$ \\
\hline VBH & Vertebral body height & $\begin{array}{l}\text { Measured on the sagittal plane of the vertebra; due to the complicated shape of the vertebra, the } \\
\text { anterior VBH was measured from most distant inferior point to the superior tip point of the } \\
\text { vertebral body cross-section; the posterior VBH was measured between two most distant points } \\
\text { of the cross-section. }\end{array}$ \\
\hline SCA & Spinal canal area & $\begin{array}{l}\text { Determined by the process described previously in the orientation of the vertebra section; } \\
\text { measured on the plane parallel to the transverse plane. }\end{array}$ \\
\hline SCW/SCD & Spinal canal width/depth & $\begin{array}{l}\text { Determined on the plane parallel to the transverse plane as the most horizontal and vertical } \\
\text { distance of two points. }\end{array}$ \\
\hline PDA & Pedicle area & $\begin{array}{l}\text { Firstly, cross-sectional plane perpendicular to the pedicle axes created in the middle of the pedicle } \\
\text { based on estimation; PDA determined by the process described previously in the orientation of } \\
\text { the vertebra section, measured on the cutting plane. }\end{array}$ \\
\hline PDH/PDW & Pedicle height/width & $\begin{array}{l}\text { Measured on the cutting plane; the width and height of the cross-sectional area of the pedicle } \\
\text { measured as the horizontal and vertical distance between the two most distant points }\end{array}$ \\
\hline
\end{tabular}

Table 1: Description of the measured parameters.

For the pedicle, both linear and area dimensions measurement of the $\mathrm{x}$-section, as shown in Figure 3, were determined.
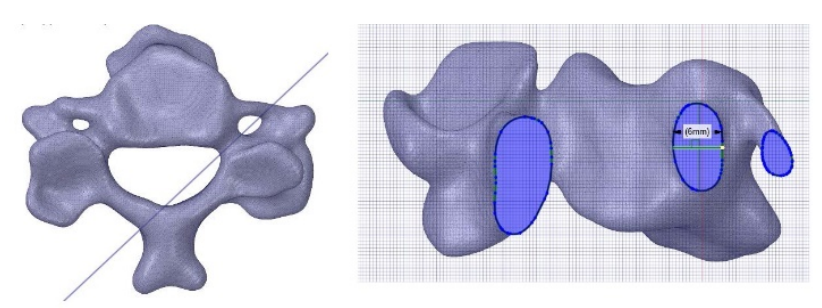

Figure 3: The process of measurement of pedicle dimensions. (A) Creation of the cutting plane perpendicularly to the pedicle axis. (B) Measurement of pedicle width on the cutting plane.

Figure 4 presents iso-, top-, front-, and side- views of cervical and thoracic vertebra highlighting the anatomical parameters with reference to the coordinate system.
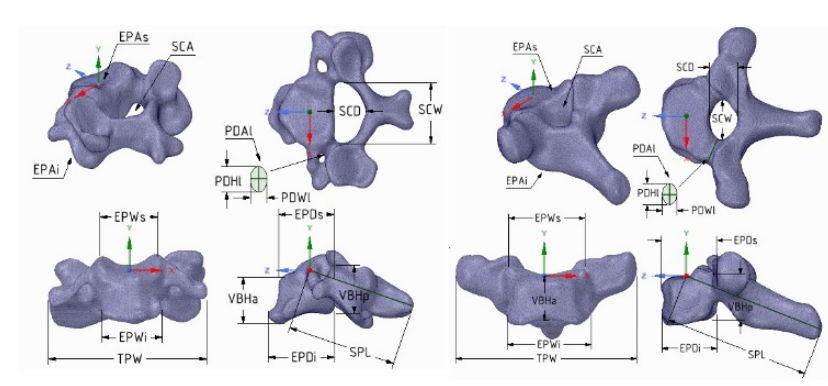

Figure 4: Four views of cervical (A) and thoracic (B) vertebrae.
In this preliminary study, only one researcher performed all measurements with each parameter obtained once only, thus standard deviation was not calculated.

\section{Results and Discussion}

Table 2 summarizes data of measured anatomical parameters based on Table 1 for vertebrae C3-T3.

\begin{tabular}{|l|l|l|l|l|l|l|l|l|}
\hline $\begin{array}{l}\text { Parameter } \\
\text { S }\end{array}$ & $\mathbf{C 3}$ & $\mathbf{C 4}$ & $\mathbf{C 5}$ & $\mathbf{C 6}$ & $\mathbf{C 7}$ & $\mathbf{T 1}$ & $\mathbf{T 2}$ & $\mathbf{T 3}$ \\
\hline TPW & 57.40 & 59.60 & 60.40 & 60.60 & 72.00 & 79.80 & 72.20 & 67.60 \\
\hline SPL & 39.56 & 41.35 & 43.51 & 51.82 & 55.26 & 64.29 & 67.00 & 65.47 \\
\hline EPWs & 20.80 & 23.00 & 26.40 & 27.60 & 30.60 & 33.60 & 31.60 & 28.80 \\
\hline EPWi & 21.80 & 23.80 & 28.20 & - & 31.60 & 37.20 & 40.00 & 37.40 \\
\hline EPDs & 20.00 & 24.60 & 25.60 & 24.42 & 26.80 & 24.60 & 24.40 & 25.80 \\
\hline EPDi & 24.00 & 25.40 & 25.60 & 25.60 & 20.01 & 24.40 & 24.40 & 28.80 \\
\hline EPAs & 336.8 & $\begin{array}{l}403.1 \\
8\end{array}$ & $\begin{array}{l}527.0 \\
8\end{array}$ & $\begin{array}{l}520.4 \\
9\end{array}$ & $\begin{array}{l}549.1 \\
0\end{array}$ & $\begin{array}{l}476.1 \\
7\end{array}$ & $\begin{array}{l}512.4 \\
9\end{array}$ & $\begin{array}{l}487.9 \\
3\end{array}$ \\
\hline EPAi & 358.1 & 450.3 & $\begin{array}{l}454.0 \\
8\end{array}$ & $\begin{array}{l}623.9 \\
3\end{array}$ & $\begin{array}{l}437.9 \\
6\end{array}$ & $\begin{array}{l}602.5 \\
8\end{array}$ & $\begin{array}{l}615.2 \\
0\end{array}$ & $\begin{array}{l}599.8 \\
4\end{array}$ \\
\hline VBHp & 17.80 & 16.40 & 15.20 & 14.00 & 16.60 & 20.08 & 21.00 & 21.40 \\
\hline VBHa & 16.80 & 13.20 & 12.60 & 14.60 & 15.40 & 21.80 & 21.40 & 22.40 \\
\hline SCW & 21.93 & 22.64 & 23.00 & 23.00 & 21.20 & 17.60 & 16.40 & 15.20 \\
\hline SCD & 11.60 & 10.57 & 11.40 & 11.40 & 9.40 & 12.25 & 14.40 & 14.00 \\
\hline SCA & 199.5 & $\begin{array}{l}178.4 \\
0\end{array}$ & $\begin{array}{l}182.7 \\
0\end{array}$ & $\begin{array}{l}182.0 \\
0\end{array}$ & $\begin{array}{l}134.6 \\
0\end{array}$ & $\begin{array}{l}156.7 \\
0\end{array}$ & $\begin{array}{l}170.4 \\
0\end{array}$ & $\begin{array}{l}150.4 \\
0\end{array}$ \\
\hline
\end{tabular}


Page 4 of 5

\begin{tabular}{|l|l|l|l|l|l|l|l|l|}
\hline PDWI & 6.60 & 7.40 & 7.50 & 6.30 & 9.60 & 12.00 & 10.20 & 8.80 \\
\hline PDWr & 6.00 & 7.20 & 7.80 & - & 10.20 & - & 9.40 & 8.60 \\
\hline PDHI & 11.00 & 10.80 & 9.40 & 9.80 & 10.40 & 15.80 & 15.40 & 15.60 \\
\hline PDHr & 10.60 & 11.40 & 10.40 & - & 8.40 & - & 15.80 & 17.20 \\
\hline PDAI & 59.50 & 62.20 & 64.00 & 51.20 & 83.10 & $\begin{array}{l}142.6 \\
0\end{array}$ & $\begin{array}{l}115.1 \\
0\end{array}$ & $\begin{array}{l}110.8 \\
0\end{array}$ \\
\hline PDAr & 50.90 & 63.50 & 64.20 & - & 70.50 & - & $\begin{array}{l}106.7 \\
0\end{array}$ & $\begin{array}{l}118.3 \\
0\end{array}$ \\
\hline
\end{tabular}

TPW as well as SPL values are greater than data presented by Tan et al. [7]. (max. difference $27.9 \%$ at C3 for TPW and $35.3 \%$ at C3 for SPL), although they follow the trend of previous study very precisely. TPW remains almost similar from C3 to C6, then linearly increases to T1 followed by a decrease to T3. SPL slightly increases along the whole spinal column from $\mathrm{C} 3$ to $\mathrm{T} 3$.

EPWs and EPWi are larger (max. difference $43.6 \%$ of EPWi at C5) than those measured by Tan et al. [7] along the whole spinal section. EPW increases until T1 (T2 in case of inferior plate) and then slightly decreases. EPD, except at $\mathrm{C} 7$, remains nearly constant. Our study shows that $\mathrm{C} 3-\mathrm{C} 7$, the posterior $\mathrm{VBH}$ is higher than the anterior $\mathrm{VBH}$. Then from C7-T3, the anterior height is higher than the posterior height. Both heights follow the similar trend as presented by Tan et al.

Table 2: Table of measured dimensions of parameters. Linear parameters unit is $[\mathrm{mm}]$, area parameters unit $\left[\mathrm{mm}^{2}\right]$.

For each vertebra, fourteen linear and five area parameters were measured. These measured data were compared to the study by Tan et al. and was shown graphically in Figure 5.

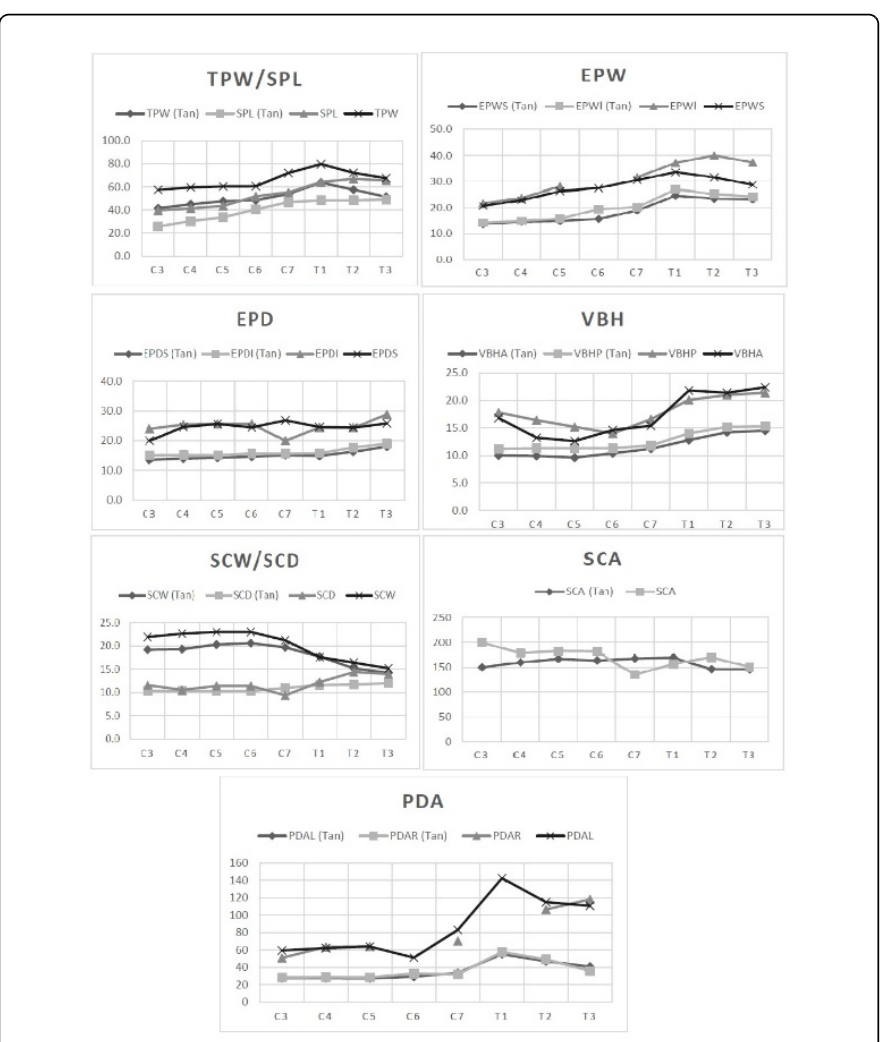

Figure 5: Comparison of linear and area parameters of present study against that of Tan et al. [7] The measured parameter is depicted as the functions of vertebral levels C3-T3.

As the specimen's spine was slightly abnormal and deformed, some dimensions were not measured.

In general, there are differences in data presented in this study and those measured by Tan et al. [7]. The measured data are considerably larger, except the spinal canal parameters. The spinal canal parameters, SCW, SCD and SCA are slightly larger, and almost similar to data presented by Tan et al. [7]. However, the measured parameters across the vertebrae $\mathrm{C} 3$ to $\mathrm{T} 3$ shows similar either increasing or decreasing trends.

Spinal canal parameters, SCW and SCD, match the results of previous study done by Tan et al. [7]. Both values are in most cases only slightly bigger (max. difference $14.8 \%$ of SCW at C4 and $18.8 \%$ of SCD at T2). Thus, the SCA is also very similar to the data measured by Tan et al. [7] Except for C7 and T1, SCA is measured slightly larger than the previous study reported.

There are some dimensions of pedicles missing due to the complicated shape of vertebrae. The PDA values are almost similar at cervical section and then sharply arise at $\mathrm{T} 1$ followed by decrease to T3.

\section{Conclusion}

In this paper we have presented the use of CT scans for reconstruction of 3D model of vertebra which serves for precise and illustrative measurement of dimensions. We used only one head and torso CT scan images of one cadaveric specimen, and measured fourteen linear and five area dimensions of the vertebrae C3-T3. To compare the dimensions, we have set the origin of the axes with orientation of the XYZ coordinate system in the $3 \mathrm{D}$ model identical to those described in the previous works by Tan et al. [7] Panjabi et al. [3-5] and Zindrick et al. [13].

The measured data are greater than others' previous works, but the dimensions followed similar trends along the whole vertebral section. This difference may due to the origin in the ethnical groups of the examined specimens in this study and others' previous works. Many studies reported that the vertebral dimensions are greatly smaller in Asian population. To confirm this hypothesis and to obtain statistically reliable data, further studies on more specimens are needed.

The method described in this paper presents a precise, 3D, illustrative way of obtaining the anatomical parameters. This method allows measurement of 3D parameters of CT scan images of living human, cadaveric specimens and embalmed specimens. As the measurement is performed on living patients, the in vivo parameters are measured. Moreover, unlike the 3D measurement on physical cadavers' specimens, the measurements on any anatomical plane are possible. Furthermore, by adopting the same coordinate system and the defined parameter, detailed statistical analysis across all types of specimens are also possible. The method can be also performed using different software with various possibilities of measurement and model reconstruction. Chen et al. has used similar technique of 3D model reconstruction using $\mathrm{CT}$ scans focusing on screw fixation parameters for anterior transpedicular screw fixation [17]. 
Citation: $\quad$ Teo EC, Holsgrove T, Haiblikova S (2017) 3D Morphometric Analysis of Human Vertebrae C3-T3 Using CT Images Reconstruction. J Spine 6: 391. doi:10.4172/2165-7939.1000391

Page 5 of 5

Further objective is to include more specimens in the study to obtain accurate, statistical and comparable data. Furthermore, to clarify whether the origin of different ethnical groups show significant differences of various anatomical parameters.

\section{Acknowledgements}

This research is supported by School of Mechanical and Aerospace Engineering of Nanyang Technological University, Singapore [Rekindle Seed Grant].

\section{References}

1. Devi R, Rajagopalan N (2003) Dimensions of the lumbar vertebral canal. Indian J Orthop 37: 13.

2. Gour KK, Shrivastava SK, Thakare AE (2011) Size of cervical vertebral canal - Measurements in lateral cervical radiographs dried bones. Int J Biol Med Res 2: 778-780.

3. Panjabi MM, Duranceau J, Goel V, Oxland T, Takata K (1991) Cervical human vertebrae quantitative three-dimensional anatomy of the middle and lower regions. Spine 16: 861-869.

4. Panjabi MM, Goel V, Oxland T, Takata K, Duranceau J, et al. (1992) Human lumbar vertebrae quantitative three-dimensional anatomy. Spine 17: 299-306.

5. Panjabi MM, Takata K, Goel V, Federico D, Oxland T, et al. (1991) Thoracic human vertebrae. Quantitative three-dimensional anatomy. Spine 16: 888-901.

6. Sengul G, Kadioglu HH (2006) Morphometric anatomy of the atlas and axis vertebrae. Turkish Neurosurgery 16: 69-76.

7. Tan SH, Teo EC, Chua HC (2004) Quantitative three-dimensional anatomy of cervical, thoracic and lumbar vertebrae of Chinese Singaporeans. Eur Spine J 13: 137-146.
8. Kathole MA, Joshi RA, Herekar NG, Jadhav S (2012) Dimensions of cervical spinal canal and vertebrae and their relevance in clinical practice. IJRTSAT 3: 54-58.

9. Schaik JJP, Verbiest H, Schaik FDJ (1985) Morphometry of lower lumbar vertebrae as seen on CT scans: Newly Recognised Characteristics. AJR 145: 327-335.

10. Gilad I, Nissan M (1985) Sagittal radiographic measurements of the cervical and lumbar vertebrae in normal adults. Br J Radiol 58: 1031-1034.

11. Hayashi $\mathrm{Y}$, Kushida K, Kitazawa A, Tanizawa T, Hotokebuchi $\mathrm{T}$, et al. (1998) Measurement of vertebral body dimensions of the thoracic and lumbar spines of 242 healthy women. J Bone Miner Metab 16: 27-33.

12. Janjua MZ, Muhammad F (1989) Measurements of the normal adult lumbar spinal canal. J Pak Med Assoc 39: 264-268.

13. Zindrick MR, Wiltse LL, Doornik A, Widell EH, Knight GW, et al. (1987) Analysis of the morphometric characteristics of the thoracic and lumbar pedicles. Spine 12: 160-166.

14. Busscher I, Ploegmakers JJW, Verkerke GJ, Veldhuizen AG (2010) Comparative anatomical dimensions of the complete human and porcine spine. Eur Spine J 19: 1104-1114.

15. Yusof MI, Ming LK, Abdullah MS (2007) Computed tomographic measurement of cervical pedicles for transpedicular fixation in a Malay population. J Orthop Surg 15: 187-190.

16. Zhou SH, McCarthy ID, McGregor AH, Coombs RRH, Hughes SPF (2000) Geometrical dimensions of the lower lumbar vertebrae - analysis of data from digitised CT images. Eur Spine J 9: 242-248.

17. Chen C, Ruan D, Wu C, Wu W, Sun P, et al. (2013) CT morphometric analysis to determine the anatomical basis for the use of transpedicular screws during reconstruction and fixations of anterior cervical vertebrae. PLoS ONE 8: e81159. 